\title{
Improvement of Physiological Characteristic of Selenium-Enriched Candida utilis with Amino Acids Addition
}

\author{
Ge Xiaoguang, Wang Dahui, Wei Gongyuan, Nie Min, and Shao Na \\ School of Basic Medicine and Biological Science, College of Medicine, Soochow University, Suzhou 215123, China \\ Correspondence should be addressed to Wei Gongyuan, weigy@suda.edu.cn
}

Received 13 July 2010; Revised 24 August 2010; Accepted 1 September 2010

Academic Editor: Igor Kovalchuk

Copyright () 2011 Ge Xiaoguang et al. This is an open access article distributed under the Creative Commons Attribution License, which permits unrestricted use, distribution, and reproduction in any medium, provided the original work is properly cited.

The effects of amino acids addition on cell growth, glutathione biosynthesis, glutathione distribution, and the intracellular oxidation-reduction environment of Candida utilis SZU 07-01 during selenium enrichment were investigated in this study. Most amino acids under appropriate concentrations have positive effects on cell growth of the yeast strain, except for phenylalanine and proline, compared with the control without amino acid addition. The bioconversion of selenite to organic selenium induced the reduction of glutathione synthesis and intracellular distribution of glutathione. However, amino acids including cysteine, glutamine, glutamic acid, isoleucine, leucine, and tyrosine could effectively promote the selenium-enriched yeast to elevate glutathione production, especially increasing the intracellular glutathione content. Moreover, addition of these six different amino acids apparently decreased malondialdehyde concentration and recovered the normal intracellular redox environment of the selenium-enriched C. utilis SZU 07-01. The improvement of physiological characteristic of the selenium-enriched yeast by increasing intracellular glutathione content and lowering malondialdehyde content will undoubtedly help to widen application of selenium-enriched yeast as food or feed additives.

\section{Introduction}

Selenium is an essential nutritional trace element for many mammalian species including human beings owing to its critical role involved in cell metabolism [1]. Selenium is also an essential component of the active site of selenoenzyme glutathione peroxidase [2]. This enzyme, together with catalase and superoxide dismutase, protects cells against damages caused by free radicals and lipid peroxides [3]. Selenium is now being widely studied for its cancer chemopreventive activity and antioxidative property [4], and it also has a profound effect on survival of HIV-infected patients [5]. In mammals, selenium deficiency has been associated with human diseases including muscular, neurological, and immune disorders, and also with increased cancer incidence and mortality $[1,6]$.

The deficiency of selenium in the diet is compensated for supplementation [7]. However, selenium can be either essential or toxic depending on its chemical form and concentration, and its safety and efficacy may also be markedly dynamic because of differential metabolic processing by different organs. It is generally believed that the ingestion of organic selenium compounds is better and safer than that contained inorganic selenium [8]. Many organic and inorganic selenium materials have been investigated as selenium supplements. Among them, supplementation by using selenium-enriched microorganisms has received much attention in recent years [9]. Researchers have found that yeast is a good carrier for selenium biotransformation. Under appropriate conditions, yeast is capable of producing biomass with high protein content and meanwhile accumulating large amount of trace elements such as selenium, and transforming inorganic selenium (low bioavailability, potentially toxic) into organic form (safer and highly bioactive), mostly in the form of selenomethionine [8].

In June 2000, selenium-enriched yeast was approved by FDA as a source for feed-supplemented organic selenium for chickens [10], which can also provide antioxidant protection at a level greater than inorganic selenium for chickens and other livestock [11]. Organic selenium from seleniumenriched yeast has been applied to the improvement of meat quality [12], growth of feathers [13], and positive influence 
of thyroxine conversion to tri-iodothyronine and passive immunity of newborn lambs [14]. Hence, the commercial demand for selenium-enriched yeast in the future will increase gradually.

Glutathione, a low-molecular thiol compound found in most plants, animals and microorganisms, fulfills its roles in many cellular processes including the protection of DNA, proteins, and other biomolecules against oxidative damage caused by reactive oxygen species [15]. Glutathione has elicited many interests in the fields of medical treatment, health care, therapeutics, sports nutrition, feed additive and cosmetics industry [16]. Glutathione can be synthesized by chemical method, enzymatic reaction, and microorganism fermentation [17]. Among these methods, yeast fermentation is more efficient and practical. Microorganisms such as Saccharomyces cerevisiae and Candida utilis are commonly used for fermentative production of glutathione $[18,19]$.

Based on the physiological function of glutathione on living organisms, the application of selenium-enriched yeast will be greatly expanded if the yeast contained glutathione intracellularly. However, most previous works on seleniumenriched yeast were carried out by S. cerevisiae, in which low yield of biomass and conversion rate of inorganic selenium were major obstacles for successful commercialization of this microorganism in the health food and feed industry [9]. So, we paid close attention to screening other industrial used yeast of $C$. utilis for selenium-enriched yeast preparation, and have found that $C$. utilis has a higher conversion rate from inorganic selenium to organic form, together with less ethanol formation during the cultivation [20]. Before our studies, few reports were focused on this aspect to date, nor with the quality improvement of selenium-enriched $C$. utilis. Moreover, the intracellular glutathione content in yeast cells was rarely explored although total selenium content was more concerned. Here, we investigated the effects of amino acids addition on the preparation of selenium-enriched C. utilis, with special emphasis on the enhancement of intracellular glutathione content of the selenium-enriched yeast in order to improve its application as food or feed additives.

\section{Materials and Methods}

2.1. Yeast Strain and Medium. C. utilis SZU 07-01, a strain which can produce glutathione intracellularly together with great ability to absorb selenium, was used in this study. The yeast strain was maintained at $4^{\circ} \mathrm{C}$ by being monthly subcultivated on the slant with seed medium $(20 \mathrm{~g} / \mathrm{L}$ glucose, $20 \mathrm{~g} / \mathrm{L}$ peptone and $10 \mathrm{~g} / \mathrm{L}$ yeast extract, $\mathrm{pH} 6.0$ ) and $20 \mathrm{~g} / \mathrm{L}$ agar.

2.2. Culture Method. The seeds were prepared by transferring colonies from a fresh agar slant into $500 \mathrm{~mL}$ Erlenmeyer flasks containing $50 \mathrm{~mL}$ seed medium, and incubated at $30^{\circ} \mathrm{C}$ for 20 hours on a rotary shaker with an agitation rate of $200 \mathrm{rpm}$. Then the culture was inoculated at $10 \%$ $(\mathrm{v} / \mathrm{v})$ into the fermentation broth. Unless stated otherwise, the medium for fermentation contained glucose $\left(30 \mathrm{gL}^{-1}\right)$, ammonium sulfate $\left(8 \mathrm{gL}^{-1}\right), \mathrm{KH}_{2} \mathrm{PO}_{4}\left(3 \mathrm{gL}^{-1}\right), \mathrm{MgSO}_{4}$ $\left(0.25 \mathrm{~g} \mathrm{~L}^{-1}\right), \mathrm{Na}_{2} \mathrm{SeO}_{3}\left(0.01 \mathrm{gL}^{-1}\right)$, with an initial $\mathrm{pH}$ of 5.5. The preparation of Se-enriched yeast was carried out in $500 \mathrm{~mL}$ flasks containing $40 \mathrm{~mL}$ fermentation medium, and the culture conditions were fixed at $27^{\circ} \mathrm{C}, 200 \mathrm{rpm}$ and $30 \mathrm{~h}$, respectively [20]. The medium was steam-sterilized except for $\mathrm{Na}_{2} \mathrm{SeO}_{3}$, which was microfiltered by a Sartorious membrane with the pore size of $0.20 \mu \mathrm{m}$.

2.3. Amino Acids Addition in Flasks. Each amino acid was added to the fermentation broth at the beginning of cultivation ( 0 hour), and the addition concentration of each amino acid shifted from $2 \mathrm{mmol} \mathrm{L}^{-1}$ to $16 \mathrm{mmol} \mathrm{L}^{-1}$. The concentrated amino acid solution was also microfiltered by a Sartorious membrane with the pore size of $0.20 \mu \mathrm{m}$. All amino acids added in this work are L-isomers, hence we omit "L-" for each amino acid in the following text.

2.4. Analytical Methods. A culture broth of $25 \mathrm{~mL}$ was centrifuged at $8,000 \times \mathrm{g}$ for 10 minutes, and after washed twice with distilled water, the wet cells were dried at $70^{\circ} \mathrm{C}$ to a constant weight for dry cell weight (DCW) determination. Glutathione was extracted from the wet cells by $40 \%(\mathrm{v} / \mathrm{v})$ ethanol solution at $30^{\circ} \mathrm{C}$ for 2 hours, then centrifuged at $8,000 \times \mathrm{g}$ for 15 minutes, the supernatant was used for glutathione assay. Glutathione concentration was determined using DTNB and glutathione reductase according to the method described by Tietze [21]. The intracellular glutathione content (IGC) of selenium-enriched yeast was defined as follows:

Intracellular glutathione content $/ \%$

$$
=\frac{\text { glutathione concentration } /\left(\mathrm{mgL}^{-1}\right)}{\operatorname{DCW}\left(\mathrm{gL}^{-1}\right) \times 10} \times 100 \% \text {. }
$$

Wet cells from a $5 \mathrm{~mL}$ culture broth were washed twice with deionized water, after centrifuged at $8,000 \times \mathrm{g}$ for 15 minutes, the cells were digested in $10 \mathrm{~mL}$ concentrated nitric acid and perchloric acid $(\mathrm{v}: \mathrm{v}=4: 1)$ at $100^{\circ} \mathrm{C}$ for 10 minutes. To avoid the volatilization loss of selenium, one reflux equipment was employed during the digestion process. The digested samples were diluted to a final volume of $50 \mathrm{~mL}$ with $0.1 \mathrm{~mol} \mathrm{~L}^{-1} \mathrm{HCl}$, filtered with a Sartorious membrane with the pore size of $0.20 \mu \mathrm{m}$, and the concentration of total selenium was determined with a catalytic spectrophotometry followed with the method previously described by Hao and Teng [22].

Wet cells from a $10 \mathrm{~mL}$ fermentation broth were washed three times with deionized water, then mixed with $5 \mathrm{~mL}$ ultrapure water and boiled at $100^{\circ} \mathrm{C}$ for 1 hour, the supernatant was assayed for the intracellular inorganic selenium. Organic selenium was calculated from the difference between the total selenium and inorganic selenium.

Glucose was determined by the DNS spectrometric method [23], and malondialdehyde (MDA) was determined by TBA assay [24]. The results shown from the flasks represent an average of three parallel experiments. 
TABLE 1: Comparison of parameters on the batch process with and without selenium enrichment.

\begin{tabular}{lcc}
\hline Parameters & Without selenium enrichment & With selenium enrichment \\
\hline Dry cell weight $\left(\mathrm{g} \mathrm{L}^{-1}\right)$ & $11.26 \pm 0.08$ & $10.14 \pm 0.06$ \\
Intracellular glutathione content (\%) & $0.89 \pm 0.03$ & $0.14 \pm 0.03$ \\
Extracellular glutathione $\left(\mathrm{mg} \mathrm{L}^{-1}\right)$ & $41.3 \pm 2.7$ & $60.7 \pm 3.2$ \\
Total glutathione $\left(\mathrm{mg} \mathrm{L}^{-1}\right)$ & $142.0 \pm 5.4$ & $74.6 \pm 4.6$ \\
Yield of selenium biotransformation (\%) & $0 \pm 0.0$ & $90.2 \pm 0.6$ \\
\hline
\end{tabular}

TABLE 2: Effects of amino acids addition on cell growth of selenium-enriched yeast.

\begin{tabular}{|c|c|c|c|c|c|c|c|}
\hline \multirow{2}{*}{ Amino acid $\left(\mathrm{mmol} \mathrm{L}^{-1}\right)$} & \multicolumn{6}{|c|}{ Dry cell weight $\left(\mathrm{g} \mathrm{L}^{-1}\right)$} & \multirow{2}{*}{ Maximum ratio increased (\%) } \\
\hline & 0 & 2 & 4 & 6 & 8 & 10 & \\
\hline Asp & $10.76 \pm 0.04$ & $10.52 \pm 0.03$ & $11.36 \pm 0.02$ & $11.56 \pm 0.02$ & $12.48 \pm 0.03$ & $12.25 \pm 0.01$ & 16.0 \\
\hline Leu & $9.53 \pm 0.08$ & $10.30 \pm 0.04$ & $10.43 \pm 0.03$ & $10.63 \pm 0.08$ & $10.90 \pm 0.03$ & $10.73 \pm 0.08$ & 14.4 \\
\hline Thr & $10.35 \pm 0.00$ & $10.95 \pm 0.05$ & $10.95 \pm 0.05$ & $11.55 \pm 0.05$ & $11.43 \pm 0.08$ & $11.70 \pm 0.05$ & 13.0 \\
\hline Val & $9.70 \pm 0.05$ & $10.00 \pm 0.04$ & $10.25 \pm 0.02$ & $10.55 \pm 0.05$ & $10.95 \pm 0.04$ & $10.25 \pm 0.01$ & 12.9 \\
\hline Lys & $10.23 \pm 0.03$ & $10.10 \pm 0.05$ & $10.58 \pm 0.08$ & $10.75 \pm 0.05$ & $11.13 \pm 0.03$ & $11.48 \pm 0.08$ & 12.2 \\
\hline $\operatorname{Arg}$ & $9.60 \pm 0.02$ & $9.68 \pm 0.08$ & $9.90 \pm 0.05$ & $9.95 \pm 0.02$ & $10.23 \pm 0.08$ & $10.65 \pm 0.00$ & 10.9 \\
\hline Ser & $10.76 \pm 0.04$ & $10.98 \pm 0.03$ & $11.15 \pm 0.03$ & $11.40 \pm 0.03$ & $11.73 \pm 0.03$ & $11.80 \pm 0.05$ & 9.7 \\
\hline Ile & $9.53 \pm 0.08$ & $9.95 \pm 0.05$ & $10.03 \pm 0.08$ & $10.13 \pm 0.03$ & $10.23 \pm 0.03$ & $10.43 \pm 0.08$ & 9.4 \\
\hline Gln & $9.90 \pm 0.05$ & $9.93 \pm 0.03$ & $10.00 \pm 0.05$ & $10.43 \pm 0.03$ & $10.80 \pm 0.04$ & $10.73 \pm 0.03$ & 9.1 \\
\hline His & $9.90 \pm 0.06$ & $10.20 \pm 0.06$ & $10.49 \pm 0.07$ & $10.49 \pm 0.03$ & $10.72 \pm 0.03$ & $10.69 \pm 0.07$ & 8.3 \\
\hline Glu & $10.38 \pm 0.00$ & $10.07 \pm 0.00$ & $10.31 \pm 0.01$ & $10.44 \pm 0.02$ & $10.94 \pm 0.07$ & $11.14 \pm 0.01$ & 7.3 \\
\hline Ala & $10.76 \pm 0.04$ & $10.36 \pm 0.03$ & $10.24 \pm 0.02$ & $10.80 \pm 0.03$ & $10.88 \pm 0.05$ & $11.40 \pm 0.08$ & 5.9 \\
\hline Tyr & $9.60 \pm 0.02$ & $9.70 \pm 0.10$ & $9.70 \pm 0.10$ & $9.65 \pm 0.02$ & $9.85 \pm 0.05$ & $10.00 \pm 0.05$ & 4.2 \\
\hline Cys & $9.90 \pm 0.06$ & $9.48 \pm 0.02$ & $9.63 \pm 0.07$ & $10.30 \pm 0.03$ & $10.06 \pm 0.06$ & $9.54 \pm 0.01$ & 4.0 \\
\hline Asn & $9.90 \pm 0.5$ & $9.43 \pm 0.03$ & $9.80 \pm 0.00$ & $9.85 \pm 0.02$ & $10.00 \pm 0.05$ & $10.28 \pm 0.03$ & 3.8 \\
\hline Met & $10.98 \pm 0.00$ & $11.03 \pm 0.03$ & $11.08 \pm 0.04$ & $11.13 \pm 0.02$ & $11.22 \pm 0.03$ & $11.32 \pm 0.04$ & 3.1 \\
\hline Try & $10.23 \pm 0.03$ & $9.83 \pm 0.08$ & $10.13 \pm 0.03$ & $10.25 \pm 0.02$ & $10.53 \pm 0.03$ & $10.30 \pm 0.01$ & 2.9 \\
\hline Gly & $10.38 \pm 0.00$ & $9.98 \pm 0.05$ & $10.14 \pm 0.02$ & $10.47 \pm 0.08$ & $10.54 \pm 0.08$ & $10.63 \pm 0.02$ & 2.4 \\
\hline Pro & $10.23 \pm 0.03$ & $9.93 \pm 0.03$ & $8.08 \pm 0.08$ & $8.58 \pm 0.03$ & $9.05 \pm 0.05$ & $8.98 \pm 0.08$ & -2.9 \\
\hline Phe & $10.23 \pm 0.03$ & $9.65 \pm 0.02$ & $8.80 \pm 0.00$ & $8.90 \pm 0.01$ & $9.15 \pm 0.00$ & $9.03 \pm 0.03$ & -5.7 \\
\hline
\end{tabular}

\section{Results}

3.1. Effect of Selenium Enrichment on Batch Culture of $C$. utilis SZU 07-01. The preparation of selenium-enriched yeast by cultivation of $C$. utilis SZU 07-01 was carried out in flasks, followed with the optimal nutrimental and environmental conditions as described in our previous study [20]. Under this circumstance, more than $90 \%$ of inorganic selenium was assimilated by the yeast and transformed into organic selenium. However, several parameters altered dramatically compared with the process without selenium enrichment (Table 1). For instance, DCW, total glutathione and intracellular glutathione content decreased by $10 \%$, $47 \%$ and $84 \%$, respectively. It is well known that higher intracellular glutathione content can boost the quality and application area of selenium-enriched C. utilis in food and feed industry [16], since it can fulfill organic selenium supplement together with the improvement of immunity of animals. Therefore, we should take measures such as amino acids addition to improve total glutathione and intracellular glutathione content of the Se-yeast.

3.2. Amino Acid Addition Boosted the Cell Growth of SeleniumEnriched Yeast. Amino acids, the basic units of protein and growth factor, are essential nutrient elements for the life cycle of yeast. Although C. utilis SZU 07-01 can grow well on a synthetic medium just contained glucose, ammonium and ions, it is also shown that the addition of some amino acids is beneficial to cell growth and metabolism of the yeast [25]. Whether amino acids were added or not, glucose in the culture medium was completely consumed, followed that glutathione was biosynthesized intracellularly and selenium was assimilated. As is shown in Table 2, almost all the amino acids added with appropriate concentration have positive effect on cell growth of selenium-enriched C. utilis SZU 0701 except for Phe and Pro, of which Ala, Gln, Glu, His, Ile and Ser can improve the biomass by $5 \sim 10 \%$, Arg, Leu, Lys, 
TABLE 3: Effects of amino acids addition on glutathione biosynthesis of selenium-enriched yeast.

\begin{tabular}{|c|c|c|c|c|c|c|c|}
\hline \multirow{2}{*}{ Amino acid $\left(\mathrm{mmol} \mathrm{L}^{-1}\right)$} & \multicolumn{6}{|c|}{ Glutathione (mg L ${ }^{-1}$ ) } & \multirow{2}{*}{ Maximum ratio increased (\%) } \\
\hline & 0 & 2 & 4 & 6 & 8 & 10 & \\
\hline Cys & $66.2 \pm 1.6$ & $74.8 \pm 0.4$ & $79.5 \pm 2.6$ & $92.8 \pm 0.3$ & $109.2 \pm 2.2$ & $134.2 \pm 1.7$ & 102.7 \\
\hline Ala & $73.1 \pm 2.5$ & $94.8 \pm 1.7$ & $130.4 \pm 2.5$ & $68.8 \pm 0.6$ & $78.9 \pm 1.2$ & $63.8 \pm 2.1$ & 78.4 \\
\hline Asp & $73.1 \pm 2.5$ & $47.6 \pm 0.6$ & $97.6 \pm 1.6$ & $121.1 \pm 2.1$ & $58.7 \pm 0.8$ & $75.7 \pm 1.2$ & 65.7 \\
\hline Glu & $82.0 \pm 0.7$ & $69.7 \pm 0.5$ & $90.1 \pm 0.0$ & $105.8 \pm 0.3$ & $110.6 \pm 4.7$ & $127.2 \pm 0.4$ & 55.1 \\
\hline Gln & $71.4 \pm 1.2$ & $72.6 \pm 1.6$ & $71.0 \pm 2.4$ & $81.3 \pm 0.2$ & $93.5 \pm 1.1$ & $106.9 \pm 1.3$ & 49.7 \\
\hline Leu & $77.0 \pm 1.1$ & $73.2 \pm 1.2$ & $93.7 \pm 0.5$ & $98.8 \pm 0.6$ & $109.8 \pm 1.7$ & $115.1 \pm 2.5$ & 49.5 \\
\hline Met & $87.5 \pm 1.5$ & $94.5 \pm 2.2$ & $101.4 \pm 1.6$ & $108.4 \pm 1.2$ & $118.6 \pm 2.6$ & $130.7 \pm 3.4$ & 49.4 \\
\hline Tyr & $62.1 \pm 1.8$ & $60.9 \pm 0.1$ & $73.8 \pm 0.3$ & $82.2 \pm 0.0$ & $82.5 \pm 4.9$ & $91.9 \pm 1.4$ & 48.0 \\
\hline Arg & $62.1 \pm 1.8$ & $70.4 \pm 2.6$ & $66.4 \pm 2.0$ & $77.0 \pm 2.1$ & $86.0 \pm 1.6$ & $77.9 \pm 2.3$ & 38.5 \\
\hline Ile & $77.0 \pm 1.1$ & $80.6 \pm 1.0$ & $88.1 \pm 2.0$ & $93.7 \pm 0.3$ & $102.4 \pm 1.0$ & $101.3 \pm 2.1$ & 33.0 \\
\hline Val & $61.4 \pm 0.7$ & $69.9 \pm 0.4$ & $71.1 \pm 1.2$ & $71.3 \pm 2.1$ & $76.2 \pm 0.6$ & $79.6 \pm 2.6$ & 29.6 \\
\hline Try & $88.1 \pm 1.9$ & $91.3 \pm 0.6$ & $95.6 \pm 0.3$ & $96.2 \pm 4.5$ & $105.0 \pm 1.0$ & $111.0 \pm 2.7$ & 26.0 \\
\hline His & $66.2 \pm 1.6$ & $72.7 \pm 1.7$ & $76.9 \pm 0.3$ & $80.7 \pm 2.4$ & $83.2 \pm 2.3$ & $82.6 \pm 1.2$ & 25.7 \\
\hline Thr & $73.5 \pm 4.6$ & $82.2 \pm 2.6$ & $77.9 \pm 2.4$ & $78.7 \pm 0.8$ & $84.7 \pm 2.2$ & $85.6 \pm 3.2$ & 16.5 \\
\hline Ser & $73.1 \pm 2.5$ & $57.2 \pm 1.7$ & $67.6 \pm 0.4$ & $74.6 \pm 0.4$ & $84.0 \pm 0.4$ & $81.0 \pm 2.4$ & 14.9 \\
\hline Gly & $82.0 \pm 0.7$ & $64.5 \pm 0.9$ & $70.1 \pm 0.4$ & $77.2 \pm 1.7$ & $92.5 \pm 2.5$ & $90.5 \pm 1.3$ & 12.8 \\
\hline Asn & $71.4 \pm 1.2$ & $63.6 \pm 1.1$ & $69.7 \pm 0.5$ & $68.3 \pm 0.9$ & $71.6 \pm 1.8$ & $75.0 \pm 2.2$ & 4.7 \\
\hline Phe & $88.1 \pm 1.9$ & $80.6 \pm 2.5$ & $75.0 \pm 3.7$ & $78.4 \pm 0.3$ & $82.2 \pm 2.0$ & $85.2 \pm 0.3$ & -3.3 \\
\hline Lys & $78.0 \pm 0.8$ & $66.4 \pm 1.8$ & $69.7 \pm 0.7$ & $67.3 \pm 1.4$ & $64.1 \pm 0.4$ & $66.8 \pm 0.0$ & -10.6 \\
\hline Pro & $78.0 \pm 0.8$ & $45.5 \pm 1.8$ & $29.7 \pm 3.0$ & $21.8 \pm 0.9$ & $31.8 \pm 1.1$ & $36.2 \pm 0.7$ & -41.7 \\
\hline
\end{tabular}

Thr and Val can increase cell growth by $10 \sim 15 \%$. Specially, DCW of selenium-enriched C. utilis SZU 07-01 was elevated by $16 \%$ when $8 \mathrm{mmol} / \mathrm{L}$ of Asp was added to the medium at the beginning of cultivation.

\subsection{Effect of Amino Acids Addition on Glutathione Biosynthesis} during Selenium Enrichment. Glutathione is biosynthesized with its precursors (glutamic acid, cysteine and glycine) and ATP, hence the addition of precursor amino acids in accordance with appropriate concentration is associated with increased glutathione biosynthesis. However, the assimilation of selenite by yeast cells will also facilitate the excretion of glutathione to the outer broth. The process of glutathione biosynthesis including total glutathione, intracellular glutathione and extracellular glutathione was investigated when the precursors and other amino acids were added during the preparation of selenium-enriched C. utilis SZU 07-01. It was found in Table 3 that just adding Lys, Phe and Pro have no positive effect on glutathione synthesis when inorganic selenium was biotransformed into organic forms. Other amino acids can increase glutathione yield if they were added in appropriate concentrations. His, Ser, Thr and Try can increase glutathione synthesis by $10 \sim 30 \%$, Arg, Gln, Ile, Leu, Met and Tyr can elevate glutathione by $30 \sim 50 \%$, Ala, Asp and Glu can boost glutathione yield by more than $50 \%$. Specially, cysteine, the key amino acid during glutathione synthesis, has a prominent ability to improve glutathione by $102.7 \%$.

3.4. Effect of Amino Acids Addition on the Distribution of Glutathione. Although many amino acids can boost total glutathione biosynthesis even in the presence of selenite, the intracellular glutathione content after adding different amino acids varied dramatically. It can be calculated from Table 4 that most of amino acids except Asn and Lys had positive effect on intracellular glutathione content of seleniumenriched C. utilis SZU 07-01. Moreover, the tendency of glutathione distribution extracellularly altered opposite to intracellular glutathione content. Among all the amino acids we considered, Cys, Glu, Ile, Leu were helpful in resistance of glutathione leakage to outer broth, and Leu was the most prominent one to promote intracellular glutathione content, together with intracellular distribution of glutathione, when compared with the control without amino acid addition within the process of selenium enrichment by C. utilis SZU 07-01.

3.5. Effect of Amino Acids Addition on the Intracellular Oxidation-Reduction Environment. During selenium enrichment of $C$. utilis SZU 07-01, more reduced glutathione was excreted to the outer cells and transformed to oxidized form. The decrease in reduced glutathione content may decrease the activities of antioxidant enzymes and so it aggravates the effect of oxidative stress [26]. The intracellular oxidation-reduction environment was represented with the inner concentration of malondialdehyde (MDA) in this study. It was illustrated in Figure 1 that Cys, Gln, Glu, Ile, Leu and Tyr which have significant effects on promoting the intracellular glutathione content and making more glutathione be distributed intracellularly can also apparently reduce MDA concentration and recover the intracellular redox environment of selenium-enriched of C. utilis 07-01. 


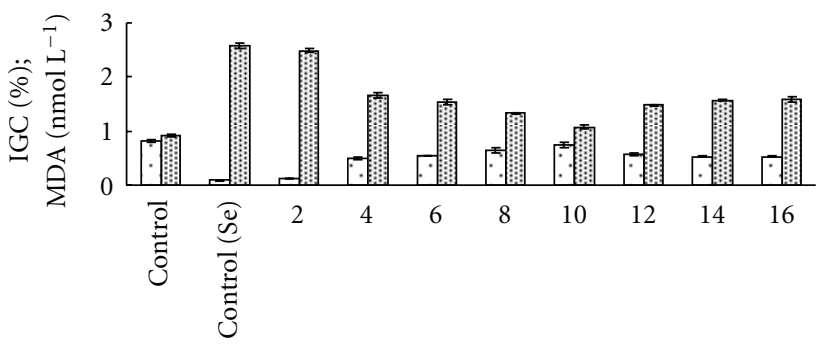

(a)

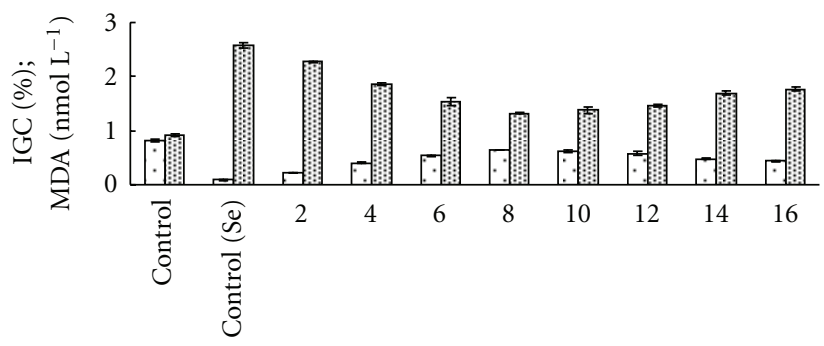

(c)

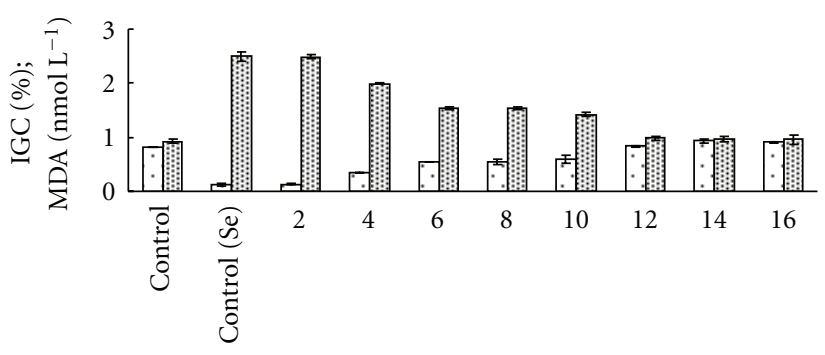

$\square \quad$ IGC

国 MDA

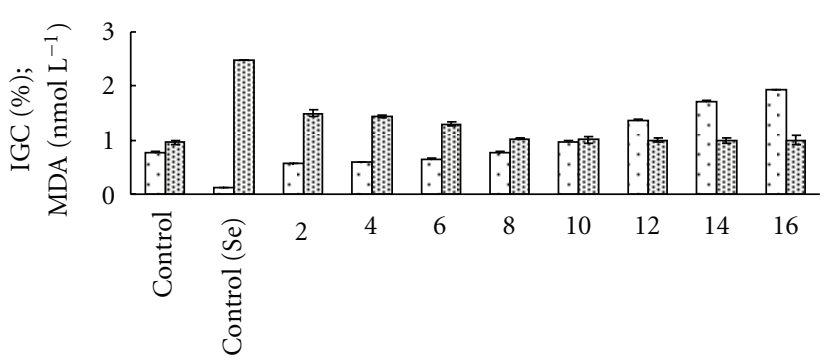

(b)

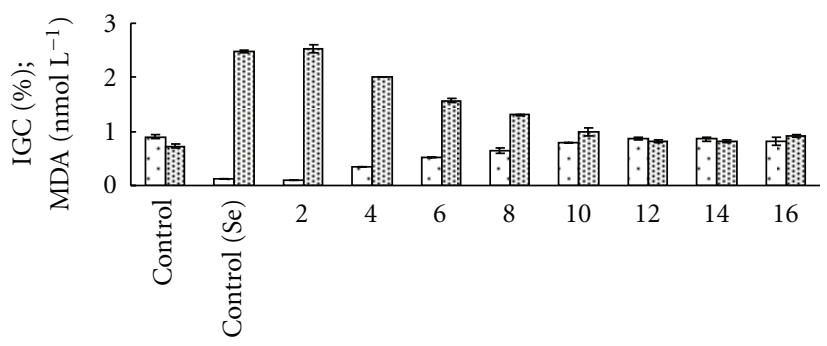

(d)

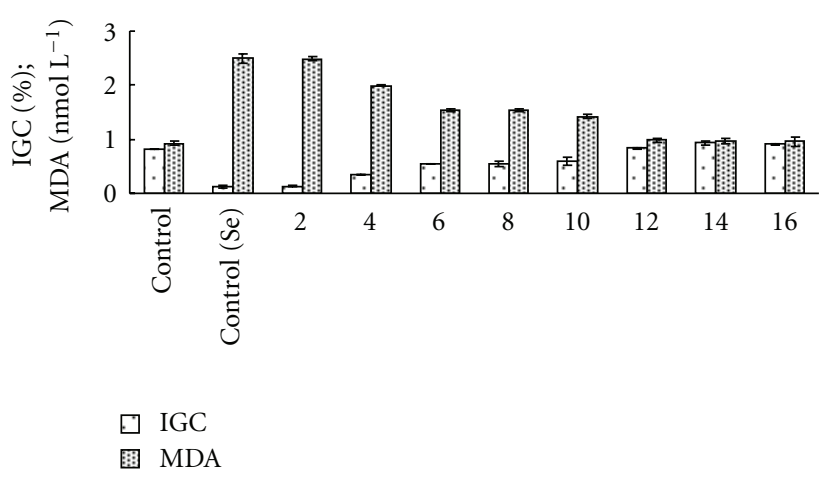

(f)

Figure 1: Effects of different concentration of amino acids ((a), Leu; (b), Cys; (c), Gln; (d), Glu; (e), Ile; (f), Tyr) addition on intracellular glutathione content and MDA concentration during selenium-enriched C. utilis SZU 07-01 preparation. The control represents batch culture without selenium enrichment; the control (Se) represents batch culture with selenium enrichment but without amino acids addition.

The more intracellular content of glutathione was detected, the less concentration of inner MDA was observed.

\section{Discussion}

More than $90 \%$ of selenium assimilated in seleniumenriched yeast involving C. utilis existed in the form of selenomethionine [8]. The metabolic pathway from selenomethionine to selenocysteine could provide Se-cysteine for the active site of glutathione peroxidase, which could enhance the enzymatic activity and thus promote the oxidation of glutathione. Moreover, selenium of low valence could be oxidized to higher oxidation state by $\mathrm{O}_{2}, \mathrm{H}_{2} \mathrm{O}_{2}$ and other peroxides, which could produce reactive oxygen species (ROS). ROS and selenium of high valence could be reduced further by glutathione. Therefore, with the biotransformation of selenium, the more selenium was absorbed to inner cells, the less intracellular glutathione was reserved and the more ROS was formed. Besides, selenite could also induce the leakage of glutathione to the outer broth during selenium enrichment [27].

Glutathione is one of the most important compounds in maintaining intracellular thiol status. It performs various functions ranging from cellular metabolism to transport and also protection against oxygen-free radicals [28]. Therefore the reduction of intracellular glutathione content would break the delicate balance between the prooxidant forces and antioxidant defenses which is known as the redox balance. When the antioxidant defenses are overwhelmed by prooxidants, oxidative stress may occur and so aggravate the effects of oxidative stress [26]. Under high oxidative stress, the production and accumulation of lipid peroxidation could be increased due to the increase of ROS. Damage to mitochondria induced by lipid peroxidation can lead to further generation of ROS [29]. In addition, increased lipid peroxidation can lead to the production of MDA that would enhance the formation of free radicals from polyunsaturated fatty acids in cell membranes and cause depletion of glutathione through detoxification by glutathione peroxidase 
TABLE 4: The ratio of extracellular glutathione decreased with amino acids addition.

\begin{tabular}{|c|c|c|c|c|c|c|c|}
\hline \multirow{2}{*}{ Amino acid $\left(\mathrm{mmol} \mathrm{L}^{-1}\right)$} & \multicolumn{6}{|c|}{ The ratio of extracellular glutathione (\%) } & \multirow{2}{*}{ Maximum ratio decreased (\%) } \\
\hline & 0 & 2 & 4 & 6 & 8 & 10 & \\
\hline Cys & $80.6 \pm 0.3$ & $28.6 \pm 0.5$ & $28.8 \pm 0.4$ & $28.0 \pm 0.3$ & $29.2 \pm 0.1$ & $30.9 \pm 0.2$ & 65.3 \\
\hline Glu & $83.3 \pm 0.2$ & $84.6 \pm 0.5$ & $61.0 \pm 0.0$ & $47.7 \pm 0.4$ & $36.0 \pm 0.3$ & $31.6 \pm 0.1$ & 62.1 \\
\hline Leu & $89.1 \pm 0.1$ & $82.2 \pm 0.3$ & $45.4 \pm 0.2$ & $41.9 \pm 0.5$ & $36.8 \pm 0.4$ & $30.3 \pm 0.2$ & 66.0 \\
\hline Ile & $89.1 \pm 0.1$ & $72.5 \pm 0.3$ & $54.1 \pm 0.5$ & $41.4 \pm 0.2$ & $36.2 \pm 0.1$ & $36.8 \pm 0.4$ & 59.4 \\
\hline Tyr & $80.9 \pm 0.4$ & $79.8 \pm 0.4$ & $54.3 \pm 0.2$ & $35.8 \pm 0.1$ & $35.4 \pm 0.2$ & $35.3 \pm 0.4$ & 56.4 \\
\hline Asp & $78.0 \pm 0.4$ & $74.1 \pm 0.1$ & $41.6 \pm 0.3$ & $39.7 \pm 0.4$ & $81.9 \pm 0.5$ & $82.6 \pm 0.3$ & 49.1 \\
\hline Gln & $83.9 \pm 0.5$ & $80.6 \pm 0.3$ & $83.8 \pm 0.4$ & $74.3 \pm 0.2$ & $68.1 \pm 0.1$ & $45.0 \pm 0.1$ & 46.4 \\
\hline Thr & $79.8 \pm 0.4$ & $73.6 \pm 0.3$ & $82.0 \pm 0.1$ & $81.6 \pm 0.3$ & $48.3 \pm 0.5$ & $45.9 \pm 0.1$ & 42.5 \\
\hline Arg & $80.9 \pm 0.4$ & $63.5 \pm 0.3$ & $76.8 \pm 0.4$ & $47.0 \pm 0.5$ & $48.5 \pm 0.4$ & $62.5 \pm 0.3$ & 41.9 \\
\hline Phe & $73.0 \pm 0.4$ & $67.6 \pm 0.3$ & $53.0 \pm 0.3$ & $46.8 \pm 0.3$ & $45.9 \pm 0.5$ & $42.9 \pm 0.3$ & 41.2 \\
\hline Met & $71.1 \pm 0.1$ & $65.8 \pm 0.4$ & $61.2 \pm 0.1$ & $57.2 \pm 0.1$ & $50.0 \pm 0.3$ & $42.4 \pm 0.2$ & 40.4 \\
\hline Try & $73.0 \pm 0.4$ & $67.6 \pm 0.4$ & $59.9 \pm 0.4$ & $54.6 \pm 0.3$ & $54.4 \pm 0.1$ & $45.2 \pm 0.3$ & 38.1 \\
\hline Val & $89.4 \pm 0.2$ & $85.2 \pm 0.4$ & $84.7 \pm 0.4$ & $84.7 \pm 0.2$ & $82.8 \pm 0.4$ & $56.6 \pm 0.3$ & 36.7 \\
\hline Ala & $78.0 \pm 0.4$ & $56.8 \pm 0.4$ & $52.4 \pm 0.2$ & $67.4 \pm 0.2$ & $69.5 \pm 0.3$ & $72.8 \pm 0.4$ & 32.8 \\
\hline Pro & $83.3 \pm 0.2$ & $70.2 \pm 0.1$ & $67.5 \pm 0.3$ & $60.3 \pm 0.4$ & $66.2 \pm 0.5$ & $67.4 \pm 0.2$ & 27.6 \\
\hline Gly & $83.3 \pm 0.2$ & $94.7 \pm 0.3$ & $89.6 \pm 0.5$ & $77.8 \pm 0.4$ & $65.7 \pm 0.4$ & $62.6 \pm 0.3$ & 24.8 \\
\hline His & $80.6 \pm 0.3$ & $71.2 \pm 0.1$ & $69.3 \pm 0.2$ & $63.7 \pm 0.4$ & $63.4 \pm 0.2$ & $63.6 \pm 0.3$ & 21.3 \\
\hline Ser & $78.0 \pm 0.4$ & $82.9 \pm 0.5$ & $70.6 \pm 0.4$ & $66.0 \pm 0.6$ & $64.3 \pm 0.2$ & $64.5 \pm 0.2$ & 17.6 \\
\hline Asn & $83.9 \pm 0.5$ & $82.6 \pm 0.1$ & $83.5 \pm 0.4$ & $84.4 \pm 0.2$ & $83.9 \pm 0.3$ & $85.2 \pm 0.2$ & 1.5 \\
\hline Lys & $83.3 \pm 0.2$ & $96.2 \pm 0.1$ & $96.4 \pm 0.2$ & $96.5 \pm 0.1$ & $96.3 \pm 0.3$ & $89.5 \pm 0.3$ & -7.4 \\
\hline
\end{tabular}

and glutathione S-transferase [30]. Although selenium can induce the synthesis of metallothionein, the damage of matallothionein in scavenging free radicals could not be repaired due to very low level of intracellular glutathione content. Decrease in intracellular thiol will bring alteration of the lipid composition, which in turn may result in disrupting the organization of cell membrane, causing changes in fluidity, permeability and enzyme activities, inhibition of metabolic processes, and alterations of ion transport [31]. This may increase the leakage of glutathione from inner cells to outer broth. According to the results in Table 1, most glutathione was observed to be transferred to extracellular medium during the preparation of selenium-enriched yeast. Iizuka et al. had also found the similar phenomenon with $S$. cerevisiae [27].

It is well known that the addition of precursors of glutathione can improve the biosynthesis of this tripeptide. Other amino acids such as Met, Tyr and Asp, have positive effects on glutathione formation during selenium enrichment will result from their entering the main pathway after deamination or transamination. Hence the addition of these amino acids to the medium will consequently increase the metabolic flux to glycolysis and citric acid cycle, which, to some extent, would be in favor of excessive biosynthesis of ATP and precursors required for glutathione production. The increase of glutathione synthesis will be undoubtedly helpful to maintain a suitable oxidation-reduction environment together with the recovery of injured cell membrane caused by selenium assimilation. Some amino acids such as Leu and Phe were also beneficial for the stabilization of cell membrane [32], which in turn would reduce the loss of intracellular glutathione.

Glutathione is an important antioxidant for protecting DNA, proteins, and other biomolecules such as metallothionein which has a stronger ability to remove hydroxyl radical than glutathione against oxidative damage by reactive oxygen species [16]. The redox system depended on glutathione had been shown to play an important role in the process against oxygen stress in E. coli and S. cerevisiae, and in maintaining the intracellular redox balance [15]. Adding certain amino acids appropriately as described above could increase intracellular glutathione content and improve distribution proportion of intracellular glutathione which will be helpful to maintain proper redox environment within cells.

\section{Acknowledgments}

X. Ge and D. Wang contributed equally to this work. The authors would like to acknowledge the financial support by the National Natural Science Foundation of China (20906065), together with the Natural Science project for Universities in Jiangsu Province (09KJB530009).

\section{References}

[1] M. P. Rayman, "The importance of selenium to human health," Lancet, vol. 356, no. 9225, pp. 233-241, 2000. 
[2] J. T. Rotruck, A. L. Pope, H. E. Ganther, A. B. Swanson, D. G. Hafeman, and W. G. Hoekstra, "Selenium: biochemical role as a component of glatathione peroxidase," Science, vol. 179, no. 4073, pp. 588-590, 1973.

[3] L. Flohé, "Selenium and peroxide metabolism," Medizinische Klinik, vol. 92, no. 3, pp. 5-7, 1997.

[4] E. A. Klein, S. M. Lippman, I. M. Thompson et al., "The selenium and vitamin E cancer prevention trial," World Journal of Urology, vol. 21, no. 1, pp. 21-27, 2003.

[5] R. Kupka, G. I. Msamanga, D. Spiegelman et al., "Selenium status is associated with accelerated HIV disease progression among HIV-1-infected pregnant women in Tanzania," Journal of Nutrition, vol. 134, no. 10, pp. 2556-2560, 2004.

[6] M. P. Rayman, "Selenium in cancer prevention: a review of the evidence and mechanism of action," Proceedings of the Nutrition Society, vol. 64, no. 4, pp. 527-542, 2005.

[7] M. P. Rayman, "Dietary selenium: time to act," British Medical Journal, vol. 314, no. 7078, pp. 387-388, 1997.

[8] G. N. Schrauzer, "Selenomethionine: a review of its nutritional significance, metabolism and toxicity," Journal of Nutrition, vol. 130, no. 7, pp. 1653-1656, 2000.

[9] Á. Suhajda, J. Hegóczki, B. Janzsó, I. Pais, and G. Vereczkey, "Preparation of selenium yeasts I. Preparation of seleniumenriched Saccharomyces cerevisiae," Journal of Trace Elements in Medicine and Biology, vol. 14, no. 1, pp. 43-47, 2000.

[10] R. Federal, "Food additive permitted in feed and drinking water: selenium yeast," Federal Register, vol. 65, pp. 3582335824, 2000.

[11] K. Z. Mahmoud and F. W. Edens, "Influence of selenium sources on age-related and mild heat stress-related changes of blood and liver glutathione redox cycle in broiler chickens (Gallus domesticus)," Comparative Biochemistry and Physiology B, vol. 136, no. 4, pp. 921-934, 2003.

[12] R. D. Mateo, J. E. Spallholz, R. Elder, I. Yoon, and S. W. Kim, "Efficacy of dietary selenium sources on growth and carcass characteristics of growing-finishing pigs fed diets containing high endogenous selenium," Journal of Animal Science, vol. 85, no. 5, pp. 1177-1183, 2007.

[13] F. W. Edens, C. R. Parkhurst, G. B. Havenstein, and A. E. Sefton, "Housing and selenium influences on feathering in broilers," Journal of Applied Poultry Research, vol. 10, no. 2, pp. 128-134, 2001.

[14] M. J. Rock, R. L. Kincaid, and G. E. Carstens, "Effects of prenatal source and level of dietary selenium on passive immunity and thermometabolism of newborn lambs," Small Ruminant Research, vol. 40, no. 2, pp. 129-138, 2001.

[15] O. Carmel-Harel and G. Storz, "Roles of the glutathione- and thioredoxin-dependent reduction systems in the Escherichia coli and Saccharomyces cerevisiae responses to oxidative stress," Annual Review of Microbiology, vol. 54, pp. 439-461, 2000.

[16] H. Sies, "Glutathione and its role in cellular functions," Free Radical Biology and Medicine, vol. 27, no. 9-10, pp. 916-921, 1999.

[17] K. Sakato and H. Tanaka, "Advanced control of glutathione fermentation process," Biotechnology and Bioengineering, vol. 40, no. 8, pp. 904-912, 1992.

[18] G. Y. Wei, Y. Li, G. C. Du, and J. Chen, "Fermentation conditions of glutathionine by Candida utilis," Chinese Journal of Applied and Environmental Biology, vol. 9, pp. 642-646, 2003.

[19] L. O. Santos, T. A. Gonzales, B. T. Úbeda, and R. M. Alegre, "Influence of culture conditions on glutathione production by Saccharomyces cerevisiae," Applied Microbiology and Biotechnology, vol. 77, no. 4, pp. 763-769, 2007.
[20] X. G. Ge, G. Y. Wei, M. Nie, and N. Shao, "Studies on the conditions for preparation of selenium enriched with Candida utilis," Cereal \& Feed Industry, vol. 10, pp. 31-33, 2009.

[21] F. Tietze, "Enzymic method for quantitative determination of nanogram amounts of total and oxidized glutathione: applications to mammalian blood and other tissues," Analytical Biochemistry, vol. 27, no. 3, pp. 502-522, 1969.

[22] S. E. Hao and B. Teng, "Study on determination of selenium in selenium-yeast," Percutaneous Transluminal Coronary Angioplasty B, vol. 35, pp. 151-153, 1999.

[23] G. L. Miller, "Use of dinitrosalicylic acid reagent for determination of reducing sugar," Analytical Chemistry, vol. 31, no. 3, pp. 426-428, 1959.

[24] A. H. Waterfall, G. Singh, J. R. Fry, and C. A. Marsden, "Detection of the lipid peroxidation product malonaldehyde in rat brain in vivo," Neuroscience Letters, vol. 200, no. 1, pp. 69-72, 1995.

[25] G.-Y. Wei, D.-H. Wang, and J. Chen, "Overproduction of glutathione by L-cysteine addition and a temperature-shift strategy," Biotechnology and Bioprocess Engineering, vol. 13, no. 3, pp. 347-353, 2008.

[26] M. C. Garg, S. Ojha, and D. D. Bansal, "Antioxidant status of streptozotocin diabetic rats," Indian Journal of Experimental Biology, vol. 34, no. 3, pp. 264-266, 1996.

[27] M. Iizuka, K. Murata, and A. Kimura, "Induction of glutathione leakage from Saccharomyces cerevisiae cells by selenite," Agricultural and Biological Chemistry, vol. 52, pp. 613614, 1988.

[28] B. A. Arrick and C. F. Nathan, "Glutathione metabolism as a determinant of therapeutic efficacy: a review," Cancer Research, vol. 44, no. 10, pp. 4224-4232, 1984.

[29] D. R. Green and J. C. Reed, "Mitochondria and apoptosis," Science, vol. 281, no. 5381, pp. 1309-1312, 1998.

[30] R. M. Adibhatla, J. F. Hatcher, and R. J. Dempsey, "Phospholipase A2, hydroxyl radicals and lipid peroxidation in transient cerebral ischemia," Antioxidants and Redox Signaling, vol. 5, no. 5, pp. 647-654, 2003

[31] H. Ahsan, A. Ali, and R. Ali, "Oxygen free radicals and systemic autoimmunity," Clinical and Experimental Immunology, vol. 131, no. 3, pp. 398-404, 2003.

[32] C. K. Hu, F. W. Bai, and L. J. An, "Influence of protein amino acid composition of plasma membranes of a self-flocculating yeast on its tolerance to etnanol and the mechanism," Acta Microbiologica Sinica, vol. 44, pp. 636-640, 2004. 

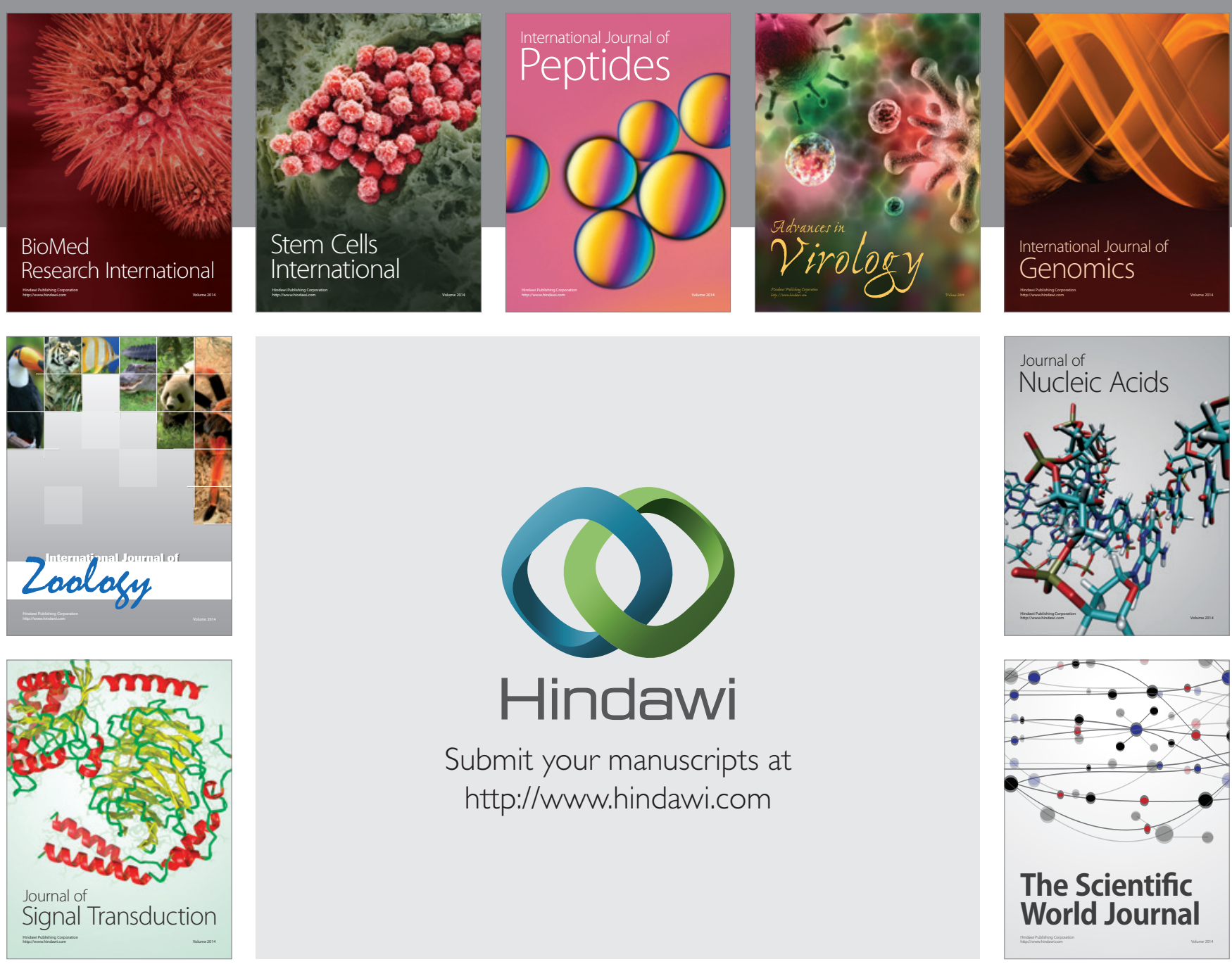

Submit your manuscripts at

http://www.hindawi.com
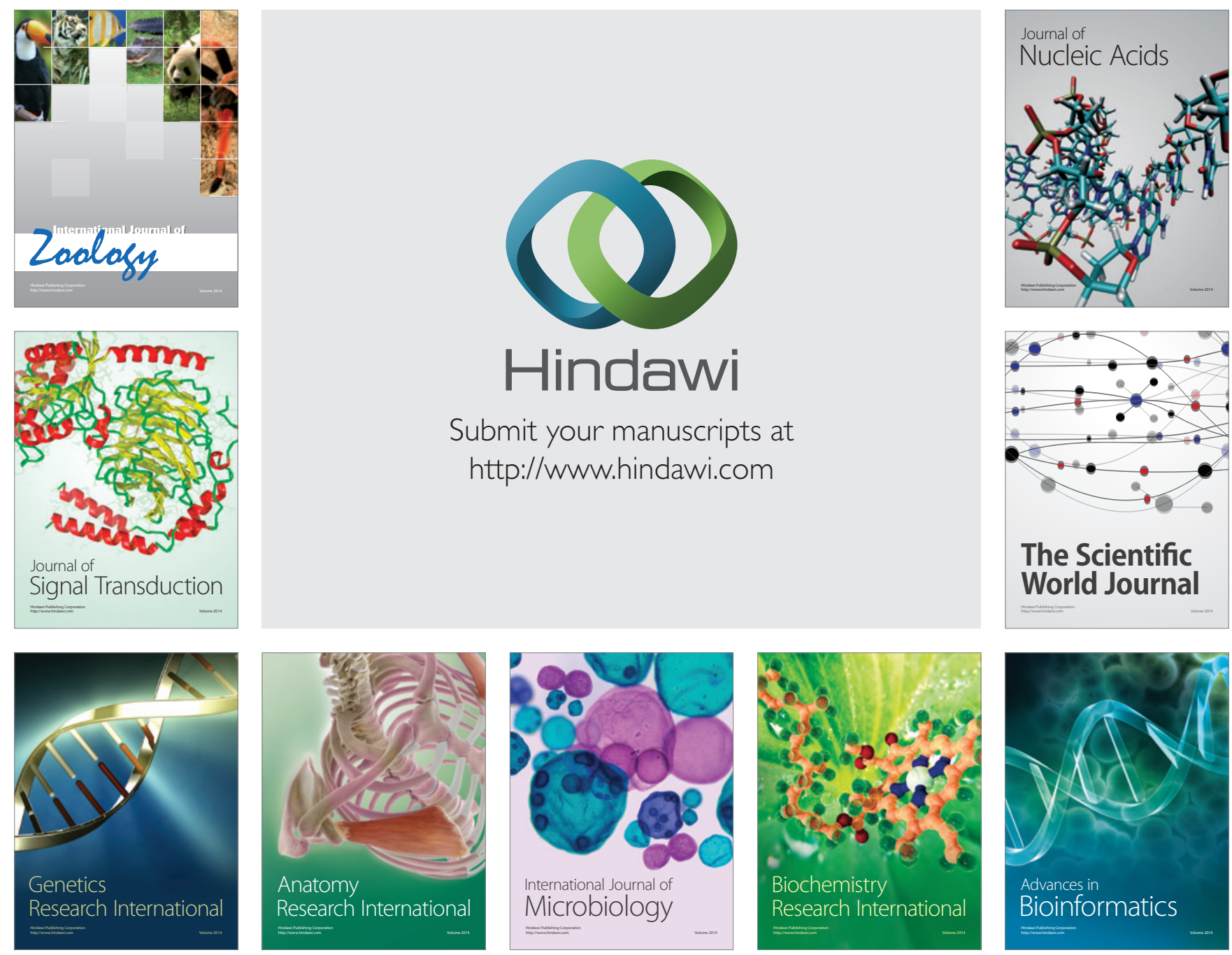

The Scientific World Journal
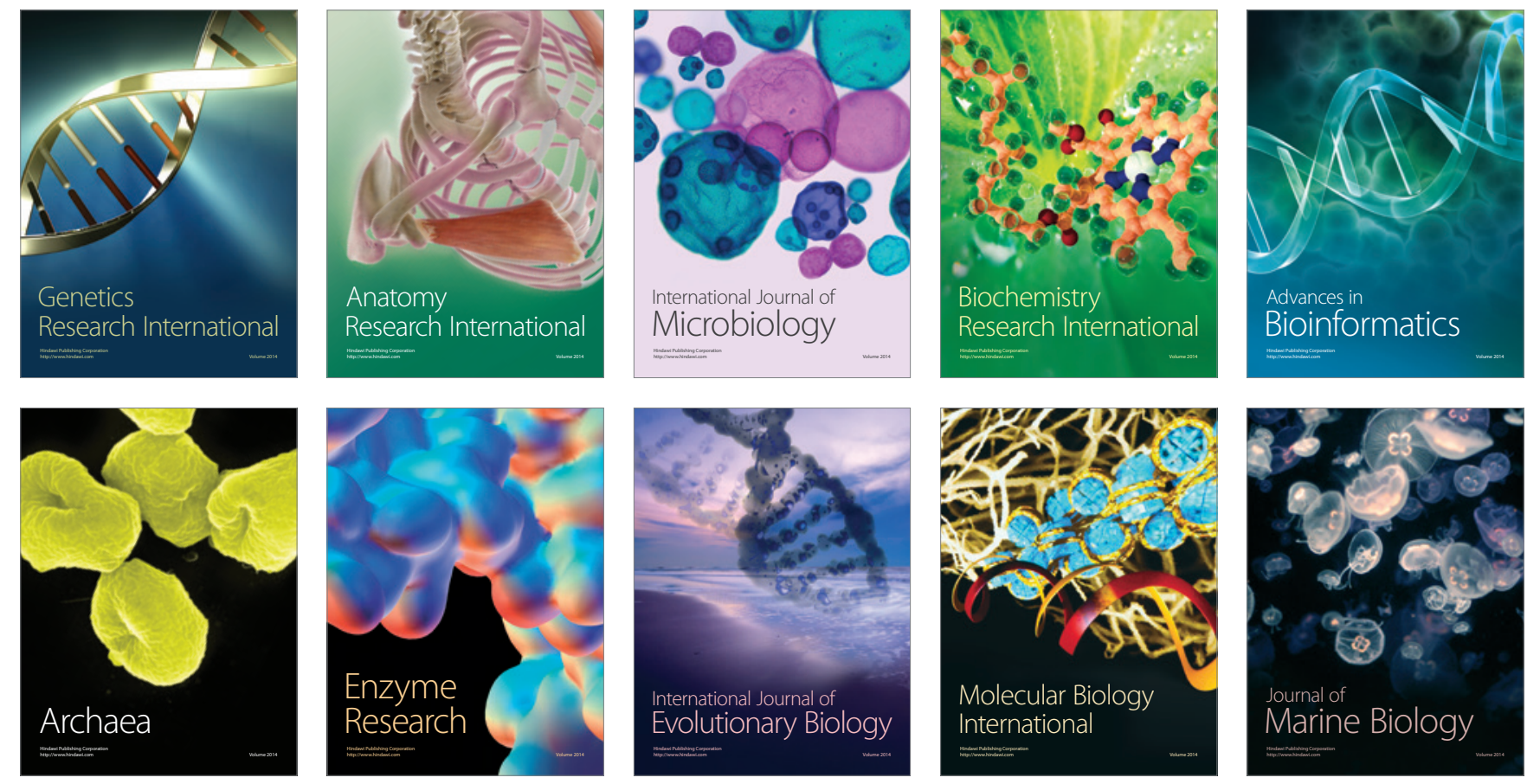